\title{
AINDA HÁ LUGAR PARA OS CLÁSSICOS \\ NA ESCOLA? - O CÂNONE E OS \\ DOCUMENTOS OFICIAIS SOBRE $O$ ENSINO DE LITERATURA
}

Marcus De Martini*

RESUMO: O presente artigo busca analisar a situação do estudo dos "clássicos" na escola, entendendo-se o termo primeiramente como referente às obras compostas entre os séculos XVI e XVIII $\mathrm{e}$, num segundo momento, estendendo-o às obras "relevantes" escritas em qualquer tempo. Com base em pesquisas recentes, como Fischer et alli. (2012) e Fischer (2014), o artigo discute a posição do "cânone" no ensino de literatura brasileira na escola analisando-se, para isso, os documentos oficiais sobre o ensino de literatura, bem como o Exame Nacional do Ensino Médio (ENEM) e o Programa Nacional Biblioteca da Escola (PNBE). A partir dessa análise, constatou-se um progressivo apagamento desse tipo de produção literária, cujas implicações são aqui discutidas. Conclui-se então que é preciso se repensar o lugar dos "clássicos" na escola, promovendo-se a formação do leitor com políticas mais consistentes e coerentes com os objetivos que se espera do ensino de literatura.

PALAVRAS-CHAVE: Ensino de Literatura; Cânone; Clássicos ENEM; PNBE.
* marcusdemartini@gmail.com

Doutor em Estudos Literarios pela Universidade Federal de Sant Maria (UFSM). Professor adjunto do Departamento de Letras

Verculas da mesma universidade.

ABSTRACT: This article aims at analyzing the current situation of the study of "classics" in school, to be understood primarily as the study of literary works composed between the Sixteenth and Eighteenth centuries and, secondarily, of the literary works considered "relevant", regardless the time when they were written. Based on recent research, such as Fischer et alli. (2012) and Fischer (2014), this article debates the place given to "canon" in the teaching of Brazilian Literature in school, by means of the analysis of the official documents on the issue, of the "Exame Nacional do Ensino Medio (ENEM)" [National High School Exam and the "Programa Necion (ENEM)" (Nib) Program for School Libreies]. From this analysis, a progressive Program for School Libraries]. From this analysis, a progressive effacement of these literary productions was perceived, whose implications are here discussed. Then, the article concludes that it is necessary to rethink the role of the "classics" in school, promoting the reader education with more consistent and coherent policies as to what is expected of the study of literature.

KEYWORDS: Teaching of Literature; Canon; Classics; ENEM; PNBE. 
1. HANSEN, Barroco, Neobarroco e outras ruínas, 2006.

\section{INTRODUÇÃO}

Tenho me dedicado há algum tempo a pensar sobre o lugar dos "clássicos" na escola hoje. Por "clássicos", entendo aquelas obras compostas dentro da comumente chamada "estética clássica" ou ainda "neoclásssica", passando pelo "barroco", rótulos esses já desmistificados por João Adolfo Hansen $^{1}$, por exemplo, mas ainda presentes nos manuais e livros escolares. Em um momento em que o estudo das práticas letradas do início de nossa literatura, como de tudo que pareça ter acumulado algum pó, paulatinamente desaparece dos próprios cursos de Letras, o que dizer da escola? Entendo perfeitamente, então, o aparente (quero crer que "aparente" seja o termo mais adequado) despropósito de minhas preocupações, a esta altura do campeonato. É claro que o fato de me dedicar academicamente ao estudo desse período é elemento determinante de meus questionamentos e inquietações; no entanto, creio que possa alargá-los, ainda que a situação ali seja menos grave, ao século XIX e ao primeiro quartel do século XX.

Sei, contudo, que o risco de parecer um renitente defensor do "cânone" - o que não é o caso - é flagrante; pois (a pergunta pulula inquieta) alguém pode questionar: por que realmente se deveria ainda estudar essas obras? Por que enfadar os jovens com tais "velharias" de nosso "museu literário", possivelmente aniquilando o interesse literário de jovens leitores em formação?
Todavia, mais que responder a essa questão, sobre a qual já me posicionei alhures ${ }^{2}$, pretendo, neste artigo, analisar as formas como as políticas de ensino de literatura (PCNs, OCEM etc.), refletindo-se no Exame Nacional do Ensino Médio (ENEM), bem como o Programa Nacional Biblioteca da Escola (PNBE), estão abordando a questão do "cânone" em geral e a dos textos do período a que me propus a tratar em específico, em alguns casos excluindo, de forma proposital ou não, o estudo de textos mais antigos de nossa literatura. Iniciarei então com a polêmica questão do "cânone" e das políticas para o ensino de literatura.

\section{ALGUMAS CONSIDERAÇÕES SOBRE O CÂNONE}

Grande parte da discussão sobre o "cânone" deve-se à ascensão da área dos Estudos Culturais. Fruto, por um lado, do Estruturalismo Francês e, por outro, da teoria literária marxista da Grã-Bretanha, os Estudos Culturais buscam estudar a cultura na amplitude de seus fenômenos, sem se ater apenas à literatura, muito menos àquelas obras que seriam as "melhores". Por isso, o interesse por obras que seriam, pelos padrões estabelecidos até então, menores, ou mesmo "não literárias", causou uma polêmica que até hoje reverbera na academia. Nesse sentido, a questão da validade ou não de se propor a existência de um "cânone" fixo passou a ter um papel fundamental ${ }^{3}$.
2. Ver DE MARTINI, Fantasmas no Sótão: as Letras Coloniais na Escola, 2016.
EM TESE
BELO HORIZONTE
v. 22
N. 3
SET.-DEz. 2016
MARTINI. Ainda há lugar para os clássicos na escola? [...]
P. $183-202$ 
4. BLOOM, O Cânone Ocidental, 1995, p. 23.

5. REIS, Cânon, 1992, p. 70

6. RECHOU, Educação literária e cânone literário escolar, 2010, p. 75.

7. RECHOU, Educação literária e cânone literário escolar, 2010, p. 70.
Uma das respostas à ascensão dos Estudos Culturais veio sobretudo a partir da polêmica obra do crítico literário norte-americano Harold Bloom O Cânone Ocidental. Como explica Bloom, "originalmente, o cânone significava a escolha de li-

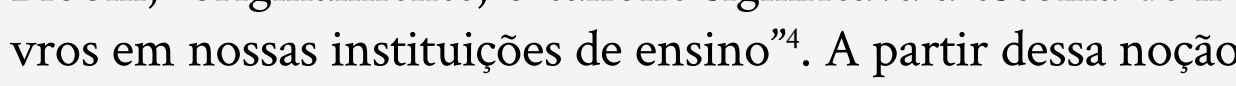
ampla, que remonta ao retor romano Quintiliano, têm-se dois elementos centrais. O primeiro é que cânone implica "escolha". Recorrendo a sua etimologia, "kanon", em grego antigo, significava uma espécie de vara de medir, que ingressou no vocabulário das línguas românicas significando "norma" ou "lei". Seu uso, inicialmente, no contexto de um cristianismo que buscava formar um corpo de crenças sólido e unificado, implicava a escolha de determinados textos em detrimento de outros, os quais passavam a ser heterodoxos, para não dizer heréticos ${ }^{5}$. A mesma noção de escolha está presente também desde a introdução do termo "cânone" na área dos estudos literários, que se teria dado com o filólogo D. Ruhnken, em 1768 que a empregou na teoria literária dos filólogos clássicos com o sentido de "lista de autores seletos de um gênero literário" E foi esse o conceito de "cânone" que se difundiu nos estudos literários, o de um "perene e exemplar conjunto de obras - os clássicos, as obras-primas dos grandes mestres - um patrimônio da humanidade" . Como sintetiza Bloom:

O Cânone, palavra religiosa em suas origens, tornou-se uma escolha entre textos que lutam uns com os outros pela sobrevivência, quer se interprete a escolha como sendo feita por grupos sociais dominantes, instituições de educação, tradições da crítica, ou, como eu faço, por autores que vieram depois e se sentem escolhidos por determinadas figuras ancestrais". 8

A partir da citação de Bloom, introduz-se o segundo elemento inerente à noção de "cânone", que é a existência de critérios de seleção. Assim, escolhiam-se determinadas obras modelares, especialmente para uso em sala de aula, com o intuito de reforçar determinadas ideias preconcebidas, que por isso, guiavam a própria escolha dessas mesmas obras, confirmando, circularmente, os critérios que presidiram sua escolha. Nesse sentido, no caso da escola, por exemplo, a existência de um cânone literário está intrinsecamente ligada ao que pretende ensinar a escola, realmente a uma "escolha”, como pontua Bloom. E a discussão sobre o cânone tem versado, na verdade, não sobre a inexistência de obras mais interessantes que outras, ou mais pertinentes para a formação do aluno, mas sobre a possibilidade de se ter critérios objetivos para a "escolha" dessas obras e o impacto que tais decisões tomam em um espectro mais amplo, no momento em que tais critérios de seleção são expostos como "naturais" ou aluno, ou, mais comumente, sequer mencionados. Acima de tudo, a questão do cânone está ligada à do "valor" de cada obra e de como auferi-lo. Por isso, por mais que se
8. BLOOM, O Cânone Ocidental, 1995, p. 28.

EM TESE BELO HORIZONTE $\quad$ v. $22 \quad$ N. $3 \quad$ Set.-DEz. $2016 \quad$ MARTINI. Ainda há lugar para os clássicos na escola? [...] $\quad$ P. 183-202

\section{Teoria da literatura e Ensino de literatura}


9. Ver GINZBURG, Cânone e valor estético numa teoria autoritaria da literatura, $2004 \mathrm{e}$ GINZBURG, O Valor Estetico: Entre Universalidade e Exclusão, 2008.

10. RECHOU, Educação literária e cânone literário escolar, 2010, p. 75.

11. BLOOM, O Cânone Ocidental, 1995, p. 33.

12. BLOOM, O Cânone Ocidental 1995 , p. 28 critique a obra e os critérios adotados nela por Bloom ${ }^{9}$, seu impacto trouxe à baila algumas questões fundamentais para os estudos literários na atualidade; como pontua Rechou, seriam elas: a constituição da história literária; os critérios nos quais se assenta uma tradição literária; o papel dos estudos literários nas sociedades avançadas; a noção de clássico o ensino da literatura nas universidades, no ensino médio e no ensino fundamental; ou o modo de integrar ideologia e estética. ${ }^{10}$ Como se vê, são todas questões inter-relacionadas, não sendo possível se tratar, como no caso do presente artigo, da literatura no ensino médio, sem esbarrar em cada uma das outras questões.

No caso do cânone literário, para Bloom, as escolhas se devem a critérios apenas estéticos, pois "toda originalidade forte se torna canônica"11. Assim, cada "grande" obra como que se imporia ao cânone, inobstante a defesa dos valores de uma crença ou classe social, fossem elas quais fossem. Ainda segundo Bloom, o questionamento de tais valores, em nome de critérios como "raça, cor e gênero", dever-se-ia à campanha do que ele chama de "Escola do Ressentimento" (feministas, afrocentristas, marxistas, neo-historicistas foucaultistas ou desconstrutores) ${ }^{12}$.

Roberto Reis, por outro lado, demonstra como os textos não são literários porque possuem atributos exclusivos, mas porque são reconhecidos como tais por seus leitores.
Nesse sentido, como defende o autor, a literatura deve ser vista como uma "praxis discursiva". Como emenda Reis, "ao olharmos para as obras canônicas da literatura ocidental percebemos de imediato a exclusão de diversos grupos sociais, étnicos e sexuais do cânon literário"13. Portanto, o processo de escolha em questão implicaria a exclusão de membros desfavorecidos em relação ao poder que exercem na sociedade. Nesse sentido, os critérios de "valor" que estariam supostamente imbricados nas escolhas das obras a compor o cânone seriam históricos e ideológicos, necessitando então serem desmascarados de sua alegada naturalidade e evidência. Contrariamente a Bloom, Reis não aceita que o texto literário possa ser considerado um "objeto estático (e estético), mas é construído em sua leitura historicamente, tendo em vista seu contexto de produção e circulação"14.

Sendo os valores mutáveis historicamente, é inevitável que o cânone também varie. Isso não quer dizer, contudo, como explica Idelber Avelar, que os valores sejam essencialmente "relativos". Apoiando-se nas ideias da filósofa Barbara Herrnstein Smith, o autor afirma que os valores são "contingentes”, isto é, nascem de uma comunidade, mas podem ser absolutos, objetivos e motivados. Isso não faz, porém, que deixem de ser contingentes; o que ocorre é que a sociedade que os engendrou passa a vê-los como não-contingentes ${ }^{15}$. Por isso, Avelar defende que, mais enriquecedor do
13. REIS, Cânon, 1992, p. 72.

14. REIS, Cânon, 1992, p. 74

5. AVELAR, Idelber. Cânone literário e valor estético: notas sobre um debate de nosso tempo, 2009, p. 135

EM TESE BELO HORIZONTE $\quad$ v. $22 \quad$ N. $3 \quad$ SET.-DEz. 2016 MARTINI. Ainda há lugar para os clássicos na escola? [...] $\quad$ P. 183-202


16. AVELAR, Idelber. Cânone literário e valor estético: notas sobre um debate de nosso tempo, 2009,

p. 146.

17. REIS, Cânon, 1992, p. 78-81.

18. “[...] esse cânone se compõe de três nacionalismos - o romântico, que incorporou parte da produção do periodo colonial (especialmente aquela ligada a algum sentimento nativista, localista, por exemplo conjunto de poetas e prosente empenhas na diničãa da nacionalidade da jovem nação independente; o republicano, que acrescentou aos românticos os classicistas (parnasianos) e os realistas (naturalistas), assim como os pensadores e ideólogos puros $\mathrm{e}$ simples, como Euclides da Cunha no primeiro caso e Ruy Barbosa no segundo; e o modernista, que incluiu parte dos escritores do começo do século sob a rubrica do pré-modernismo (nisto enquadrando, de forma rebaixada, os chamados regionalistas) ao grupo de autores vanguardistas aos que floresceram nos anos 30 , poetas, prosadores e ensaistas". FISCHER, O Filn do canone e nós com isso - Passado e presente do ensino de literatura no Brasil, 2014, p. 578. que fomentar uma disputa entre defensores e detratores do cânone, seria empreender uma "futura história da construção do valor literário no Brasil”"

Contudo, neste momento, é bom que se pergunte: enfim, qual seria o cânone literário brasileiro?

Com base nos trabalhos de Flora Süssekind, Reis identifica um processo de formação do cânone literário brasileiro a partir do século XVIII, com a conformação de um sistema literário no Brasil (segundo a tese introduzida por Antonio Candido, ainda em fins da década de 1950). Tal projeto de literatura nacional estaria atrelado às elites de letrados, a maioria com formação em Portugal, que, no contexto da Independência e depois na afirmação do Estado Nacional, encontraria justamente no nacionalismo sua ideologia de base. Mesmo um século depois do indianismo e do sertanismo românticos, tal ideário não é estranho ao Modernismo, com o adendo de que ao nacionalismo, acrescenta-se o ideal de modernização ${ }^{17}$.

Não é diferente a conclusão a que chega Luís Augusto Fischer ${ }^{18}$. Contudo, a origem desse cânone, para o autor é fruto da ascensão do vestibular unificado, na década de 1970. Os programas, que acabaram sendo levados à escola com a qual o cânone sempre se ligou, refletiram, ainda segundo o autor, um estágio de modernização da sociedade brasileira, ao qual a teoria crítica de Antonio Candido (e por extensão, Uspiana) teria respondido melhor. Tal orientação teria, segundo Fisher, erigido o lugar de destaque tomado pelo Modernismo "paulistocêntrico" desde então. Inadvertidamente, esse esquema de organização da literatura brasileira teria se tornado o verdadeiro "conteúdo" das aulas da disciplina, alijando-se os alunos do contato com os textos propriamente ditos ${ }^{19}$. A propósito, quanto a esse tipo de aula de literatura justamente insurgir-se-iam os documentos oficiais para o ensino da disciplina a partir dos PCNs, como veremos a seguir.

\section{O "CÂNONE" E OS DOCUMENTOS OFICIAIS SOBRE O}

\section{ENSINO DE LITERATURA}

Uma recuperação abrangente da história do ensino de literatura seria incompatível com a extensão deste artigo. Por isso, limitemos nossos comentários para o período que se estende a partir da publicação, em 1996, da nova Lei de Diretrizes e Bases (LDB), com uma nova organização da educação brasileira e com inovações na abordagem das disciplinas, e à disciplina de Literatura Brasileira, no Ensino Médio.

Seguiu-se à nova lei a publicação, em 1997, dos Parâmetros Curriculares Nacionais (PCNs), destinados ao ensino fundamental, e, em 1999, a dos Parâmetros Curriculares Nacionais:
19. FISCHER, O Fim do cânone e nós com isso - Passado e presente do p. 577 e segs.

EM TESE BELO HORIZONTE $\quad$ v. $22 \quad$ N. $3 \quad$ Set.-DEz. $2016 \quad$ MARTINI. Ainda há lugar para os clássicos na escola? [...] $\quad$ P. 183-202

Teoria da literatura e Ensino de Literatura 
20. Sobre o assunto, ver PAULINO, Formação de leitores: a questão dos cânones literários, 2004, O OLIVEIRA e REZENDE, Aula de literatura no ensino médio escombros do texto ou leitur literária, 2015.
Ensino Médio (PCNEM), trazendo a chamada área de "Linguagens, Códigos e suas Tecnologias", que englobaria, dentre outras matérias, os conteúdos pertinentes à área de Língua Portuguesa e Literatura. Se, no caso da Língua Portuguesa, a influência da Sociolinguística foi fundamental no caso da Literatura, a influência da Estética da Recepção, bem como dos Estudos Culturais, popularizados nas universidades brasileiras a partir dos anos 80 , ficou bem visíve ${ }^{20}$ Assim, os documentos traziam diversos avanços, que davam conta do novo contexto dos estudos da linguagem, introduzindo, por isso, pontos ainda hoje polêmicos, como a discussão do cânone e da norma culta. Quanto ao primeiro ponto, tornou-se emblemático o seguinte excerto:

[...] A história da literatura costuma ser o foco da compreensão do texto; uma história que nem sempre corresponde ao texto que lhe serve de exemplo. O conceito de texto literário é discutível. Machado de Assis é literatura, Paulo Coelho não. Por quê? As explicações não fazem sentido para o aluno ${ }^{21}$.

De fato, o documento é correto em sua avaliação de que o foco dado ao ensino de história da literatura, em vez de investir-se na formação do leitor, tem consequências funestas para esta última. No entanto, ao passo que questiona a validade do cânone, não se aprofunda no assunto. Uma vez que os gêneros literários passam a ser entendidos apenas como formas discursivas ideologicamente valorizadas, em prejuízo de outros gêneros mais próximos ao aluno, que se revolta ao ter de estudá-los, nada mais se menciona claramente sobre literatura. Assim, entre as competências e habilidades que se devem desenvolver no ensino de língua portuguesa, está a de analisar os recursos verbais, de acordo com suas condições de produção/recepção, pois, ainda segundo o documento, tanto a literatura quanto a propaganda podem se valer dos mesmos recursos. Fica claro, então, que os gêneros literários não se destacam dos demais gêneros discursivos, devendo ser estudados com vistas à identificação de recursos verbais criativos.

O texto, como não poderia deixar de ser, gerou polêmicas, e uma "continuação": os Parâmetros curriculares Nacionais + Ensino Médio (PCN+), cujo subtítulo era "Orientações educacionais complementares aos Parâmetros Curriculares Nacionais". Na esteira do documento anterior, os PCN+ afirmam que, na nova área de "Linguagens, Códigos e suas tecnologias”, "o grande objeto de estudo são as várias linguagens e os códigos por elas estruturados, nas manifestações particulares que deles se valem (textos) para estabelecer diferentes formas de comunicação"22.

$\mathrm{Na}$ defesa da necessidade da contextualização - o que é fato hoje indiscutível - o documento traz um exemplo da literatura:
EM TESE BELO HORIZONTE $\quad$ v. $22 \quad$ N. $3 \quad$ SET.-DEz. 2016 MARTINI. Ainda há lugar para os clássicos na escola? [...] $\quad$ P. 183-202
22. BRASIL, $P C N+$ Ensino Médio, 2002, p. 26.

Teoria da Literatura e Ensino de Literatura 
23. BRASIL, PCN+Ensino Médio, 2002 , p. 35
Fatos e dados são aprendidos pela memorização, pela reprodução, pela repetição.

Pode-se aprendê-los pela observação direta, pela leitura, pelo recurso a fontes diversas.

Por exemplo, o aluno pode aprender o título da obra $O$ cortiço, saber o nome do seu autor (Aluísio Azevedo), conhecer detalhes da biografia desse autor - que era um excelente desenhista, por exemplo. E pode automatizar essas informações.

Já os conceitos só se adquirem pela aprendizagem significativa. Os dados só contribuem para a aprendizagem de conceitos quando adquirem sentido. Saber o título do romance mais importante de Aluísio Azevedo é uma coisa. Relacionar esse título com o sério problema habitacional do final do século 19 no Rio de Janeiro é coisa bem diferente. Ao fazer essa relação, o dado adquire significado e o aluno amplia seu conhecimento do conceito de literatura, por exemplo. ${ }^{23}$

Mais uma vez, critica-se com razão o tipo de conhecimento reprodutivo das velhas - mas ainda vivas - aulas de história da literatura. No entanto, é preciso questionar-se até que ponto a contextualização da obra amplia necessariamente o "conceito de literatura" de que fala o documento. Até que ponto esse conhecimento não é também automatizado, numa troca de informações memorizáveis? Até que ponto isso faz do aluno em leitor melhor, e especificamente um leitor de literatura melhor?

EM TESE

\begin{abstract}
BELO HORIZONTE
\end{abstract}
v. 22
N. 3

SET.-DEZ. 2016
Todavia, apesar de os $\mathrm{PCN}+$ seguirem os pressupostos teóricos e intenções de seu antecessor, abrem espaço para o estudo histórico da literatura, o que, de fato, seria um contrassenso se não o fizesse, haja vista a ênfase em conceitos como intertextualidade, dialogismo e contexto, que permeiam o texto do documento. Assim, segundo o documento, o aluno deveria aprender a "identificar obras com determinados períodos, percebendo-as como típicas de seu tempo ou antecipatórias de novas tendências" ${ }^{24}$. E entre as competências gerais para o trabalho com o texto, tem-se "recuperar, pelo estudo do texto literário, as formas instituídas de construção do imaginário coletivo, o patrimônio representativo da cultura e as classificações preservadas e divulgadas, no eixo temporal e espacial" ${ }^{\prime 2}$.

Assim, como se vê, embora os $\mathrm{PCN}+$ não contrariem os PCNs em sua essência, trazem de volta a questão sócio-histórica para a análise do texto literário, o que, na realidade da sala de aula, sabe-se, significa a manutenção do estudo periodológico da literatura. A própria menção de "clássicos" da literatura brasileira, como O Cortiço, entre outras que pipocam pelo texto, mostra certo passo atrás e mais cautela em relação ao tratamento do cânone, em comparação aos $\mathrm{PCNs}^{26}$.

No entanto, a questão tomaria outra direção com as Orientações Curriculares do Ensino Médio, lançadas em 2004 em que há uma análise do disposto sobre literatura nos
24. BRASIL, PCN+Ensino Médio, 2002, p. 65.

5. BRASIL, PCN+Ensino Médio, 2002, p. 74. do documento, ver SEGABINAZ Orientaçöes e diretrizes para o ensino e a formação do professor de literatura, 2016

\section{Teoria da literatura e Ensino de literatura}


PCNEM assinada por Enid Yatsuda Frederico e Haquira Osakabe. O documento inicia com um interessante histórico que pretende situar a crise do ensino médio e, em meio a ela, a problemática da literatura. Segundo o texto, ao passo que a expansão do ensino, especialmente a partir dos anos 1960, teria abarcado toda uma camada da população antes alijada da escola, a incorporação dessa população mais carente implicaria, no caso da literatura, um problema, na medida em que esses alunos não teriam, comumente, contato com livros ou mesmo a possibilidade de adquiri-los. Nesse sentido, o estudo da literatura com o objetivo de formar leitores seria algo extremamente complicado, do que resultariam práticas de ensino que se distanciariam do texto propriamente dito, especialmente os do cânone. Como afirma o documento:

[...] a tentativa de atenuar o impacto da distância entre as manifestações literárias consagradas e as condições de recepção do aluno (envolvendo o repertório e a experiência linguística) resulta sempre numa redução do processo de assimilação da experiência literária em resultados tais como:

a) substituição da literatura difícil por uma literatura considerada mais digerível;

b) simplificação da aprendizagem literária a um conjunto de informações externas às obras e aos textos; c) substituição dos textos originais por simulacros, tais como paráfrases ou resumos. ${ }^{27}$

É diante desse contexto que os autores explicam o tratamento dado à literatura pelos PCNEM: no fim das contas, é melhor colocar o aluno diante de algum texto que lhe seja mais palatável, qualquer que seja ele, do que diante de simulacros e dados memorizáveis. No entanto, criticam nos PCNEM o pressuposto de que um texto literário não possa ser diferenciado de um não-literário, do mesmo modo que criticam que a opinião do aluno em relação ao texto possa ser de fato um critério absoluto. Segundo o texto, essa postura dos PCNEM, corroborada pelos $\mathrm{PCN}+$, colocaria a Literatura em uma posição secundária e mesmo dispensável, deixando o ensino de literatura fora de sintonia com as expectativas sociais, escolares e universitárias, de que o ENEM seria um exemplo manifesto (veremos isso mais adiante) ${ }^{28}$. A partir daí, os autores partem para "algumas ideias", que serão analisadas com mais detalhe no documento seguinte: as Orientações Curriculares para o Ensino Médio - linguagens, códigos e suas tecnologias, em que Enid Y. Frederico aparece como consultora, ao lado de Neide Luzia de Rezende e Maria Zélia Versiani Machado, enquanto que Haquira Osakabe aparece como "leitor crítico", ao lado de Lígia Chiappini Moraes Leite.

Surgido em 2006, o documento, uma vez que prossegue com dois dos autores das Orientações Curriculares anteriores, aprofunda as
27. FREDERICO; OSAKABE, PCNEM literatura Análise crítica, 2004, p. 63-4.

EM TESE BELO HORIZONTE $\quad$ v. $22 \quad$ N. $3 \quad$ SET.-DEz. 2016 MARTINI. Ainda há lugar para os clássicos na escola? [...] $\quad$ P. 183-202

\section{Teoria da literatura e Ensino de literatura}


29. BRASIL, Orientações curriculares para o ensino médio: Linguagens, códigos e suas tecnologias, 2006, p. 49-53.

30. BRASIL. LEI No 9394, de 20 de dezembro de 1996

31. BRASIL, Orientações curriculares para o ensino médio: Linguagens, códigos e suas tecnologias, 2006, p. 55 . colocações feitas neste último. As OCEM colocam então a disciplina de Literatura como um capitulo à parte da de Língua Portuguesa, resgatando um pouco do papel da disciplina, praticamente apagado nos documentos anteriores. Já de início, defende-se a particularidade do discurso literário, por ser o menos pragmático dos modos discursivos, o que lhe permite o "exercício da liberdade" de criar e provocar o estranhamento do leitor. Nesse sentido, a literatura seria uma área que oportunizaria ao aluno um espaço de liberdade e uma alternativa rara, no contexto do ensino médio, de desenvolver-se fora das premências do mercado de trabalho e das ingerências sobre a "utilidade prática" do que se aprende, abrindo-lhe o caminho para um ensino prazeroso e para a fruição estética ${ }^{29}$. O objetivo do ensino de literatura diria respeito então ao que trazem as $L D B$, em seu art. 35, inciso III: "III) aprimoramento do educando como pessoa humana, incluindo a formação ética e o desenvolvimento da autonomia intelectual e do pensamento crítico"30.

A partir disso, as OCEM introduzem a noção de "letramento literário" como meio para se obter tal fim, definindo-o como a tarefa de "dotar o educando da capacidade de se apropriar da literatura, tendo dela a experiência literária"31. Para isso, o contato efetivo com o texto seria determinante. Mas quais textos devem ser lidos? Aí é que entra novamente a questão do "cânone".

Como os documentos anteriores, as OCEM determinam que não se deve então "sobrecarregar o aluno com informações sobre épocas, estilos, características de escolas literárias, etc., como até hoje tem ocorrido..." ${ }^{32}$. No entanto, as OCEM reconhecem, conforme apontamos anteriormente, que os PCNEM e os PCN+ eram contraditórios nesse aspecto. De qualquer modo, segundo o mesmo documento, o professor deve trabalhar com textos de "valor estético". Com isso, as OCEM, na esteira das Orientações, fogem do tom "anticanônico" dos textos anteriores. Ao discutir um texto de Chiappini que apresenta uma dicotomia entre um professor "canônico", tido como autoritário por só trabalhar com o cânone, e um professor dito "libertário", por fugir deliberadamente dele, o texto identifica, inclusive, nessa última postura, uma possível atitude "permissiva" ou "preconceituosa", no sentido de se crer que o aluno, por exemplo, só seria capaz de entender textos mais simples ou ligados aos gêneros populares e de "consumo". Portanto, tanto se ater apenas ao cânone, quanto fugir sempre dele, seriam atitudes análogas; assim, como dito acima, o professor deveria optar por uma atitude intermediária, ou seja, a de optar por textos de "valor estético", mais que de "valor cultural". O professor deveria então fazer o seguinte escrutínio:

Qualquer texto escrito, seja ele popular ou erudito, seja expressão de grupos majoritários ou de minorias, contenha denúncias ou reafirme o status quo, deve passar pelo mesmo crivo que se utiliza para os escritos canônicos: Há ou não intencionalidade artística? A realização correspondeu à intenção? Quais
32. BRASIL, Orientações curriculares para o ensino médio: Linguagens, códigos e suas tecnologias, 2006, p. 54

EM TESE BELO HORIZONTE $\quad$ v. $22 \quad$ N. $3 \quad$ Set.-DEz. $2016 \quad$ MARTINI. Ainda há lugar para os clássicos na escola? [...] $\quad$ P. 183-202


33. BRASIL, Orientações curriculares para o ensino médio: Linguagens, códigos e suas tecnologias, 2006, p. 57.

34. FREDERICO; OSAKABE, PCNEM literatura. Análise crítica, 2004, p. 76.

35. BRASIL, Orientações curriculares para o ensino médio: Linguagens, códigos e suas tecnologias, 2006, p. 54 . os recursos utilizados para tal? Qual seu significado histórico-social? Proporciona ele o estranhamento, o prazer estético? ${ }^{33}$

No entanto, o documento reconhece, inclusive, que, em muitos casos, essa identificação é bem difícil. Mais que isso, poderíamos questionar se ela é realmente possível.

Em primeiro lugar, tanto as Orientações, quanto as OCEM, insistem em discutir a "literariedade". No primeiro documento, encontramos a noção de "estranhamento", que seria uma característica dos textos literários, que produziriam uma noção de estranheza em virtude do uso peculiar da escrita ${ }^{34}$ tese essa que remonta, como se sabe, ao Formalismo Russo. A mesma ideia ressurge nas OCEM, ainda que com menos destaque (como se vê na última citação em bloco), aproveitando-se para ressaltar que esses critérios de separação entre texto literário e não literário haviam gerado muita discussão ${ }^{35}$. No entanto, essa ideia não é, contrariamente ao que se viu nos PCNEM, infensa ao "cânone". Nas Orientações, encontramos:

Isto significa que a vida literária dentro da história cultural de um país não erige padrões eternos e por isso mesmo não define normativamente quadros definitivos de referência para a posteridade. No entanto, não é possível uma cultura sobreviver sem tais padrões. Assim, a noção de cânone guarda relação com a transitoriedade, com a época e sua fugacidade, mas, também, com a permanência. Por isso, embora nada se possa considerar definitivo em matéria de excelência estética, dificilmente se poderá considerar como gratuito o efeito de permanência de obras que mantêm, mesmo com o passar dos séculos, o vigor do momento de seu aparecimento ${ }^{36}$.

O mesmo tom conciliatório é repetido nas OCEM, onde se discute a questão da mediação da leitura pelo professor. Vale destacar que, tanto as Orientações, quanto as OCEM, defendem a seleção dos textos literários por seu critério de "literariedade", o que, como vimos, é bem discutível teoricamente. Por outro lado, não pressupõem que as obras inseridas no "cânone" sejam as únicas dotadas desse "valor" superior; no entanto, todas devem ser inseridas no horizonte possível de formação do leitor literário ${ }^{37}$.

Agora é preciso saber de que forma isso tem chegado ao ambiente escolar. A análise do ENEM vai nos dar algumas pistas a respeito.

\section{O ENEM}

Há uma tendência histórica na educação brasileira, como aponta Razzini ${ }^{38}$, em pensar-se o ensino médio em função do acesso ao superior; assim, se, por um lado, o surgimento dos vestibulares, com prova obrigatória de Literatura Brasileira, legitimou sua existência no currículo das escolas, é de se cogitar se a ascensão do ENEM e a diluição do
36. FREDERICO; OSAKABE, PCNEM - literatura. Análise crítica, 2004, p. 78.

EM TESE BELO HORIZONTE $\quad$ v. $22 \quad$ N. $3 \quad$ SET.-DEz. 2016 MARTINI. Ainda há lugar para os clássicos na escola? [...] $\quad$ P. 183-202

\section{Teoria da literatura e Ensino de literatura}


conteúdo de Literatura na área de "Linguagens, Códigos e suas Tecnologias”, com as características vistas acima, não causará o efeito contrário, prejudicando não apenas a leitura dos clássicos, mas de quaisquer outras obras ditas literárias. Por isso a necessidade de tratar-se desse assunto no presente artigo.

O Exame Nacional do Ensino Médio (ENEM) surgiu em 1998, inicialmente com o objetivo de avaliar os alunos que saíam da escola, obtendo-se assim um diagnóstico da formação que haviam recebido nessa fase final da Educação Básica. No entanto, reformulado em 2009, o ENEM adquiriu grande importância como substituto dos concursos vestibulares para ingresso nas instituições de ensino superior que optassem por adotá-lo, no todo ou em parte, para selecionarem seus candidatos.

Organizado dentro do esquema de áreas trazido pelos PCNs, o ENEM contempla os conhecimentos literários dentro da área de "Linguagens, Códigos e suas Tecnologias". Ainda que venha paulatinamente substituindo os vestibulares da grande maioria das instituições, tanto públicas, quanto privadas, o ENEM diferencia-se das provas tradicionais não só por essa divisão peculiar em áreas, mas, no caso da Literatura, em especial, pela ausência de uma característica típica das provas, especialmente dos vestibulares mais concorridos: uma lista mínima de leituras obrigatórias.
Tendência essa trazida também pelos PCNs e compreensível por seu tom "anticanônico", como já nos referimos.

Além disso, insistindo na capacidade de interpretação de textos pelo aluno, mais do em sua capacidade de memorização de informações - no que acerta -, a prova, porém, não raro, acaba por apresentar questões de literatura que prescindem, para sua resolução, de qualquer conhecimento literário específico, como o da própria historiografia, o que acaba por caracterizar esse tipo de conhecimento como algo sem importância. Foi o que concluíram Fischer [et alii.], ao analisarem as provas do ENEM de 1998 a $2010^{39}$. Pelo estudo, constata-se que, das 164 questões de Literatura encontradas no ENEM pelos pesquisadores, entre 1998 e 2010, 80\% poderiam ser respondidas sem que o aluno jamais houvesse assistido a qualquer aula da disciplina. Quanto à literatura do período que nos interessa neste artigo, qual seja, a dos séculos XVI a XVIII, a situação é pior: apenas nove ${ }^{40}$ questões abordavam textos literários anteriores ao Romantismo, o que contabiliza pouco mais de $5 \%$ das questões. Aumentando um pouco o espectro temporal, os autores constataram que, juntando-se todos os períodos literários anteriores a 1920 somam-se apenas 31 questões, o que representa cerca de 19\% do total de questões avaliadas. Enquanto isso, o Modernismo é o período com mais questões na prova: cerca de $30 \%$ do total das questões avaliadas no período da pesquisa. Assim,
39. FISCHER et ali.. $A$ Literatura no Exame Nacional do Ensino Médio (ENEM), 2012.

0. Das nove questốes, duas seriam sobre Classicismo, duas sobre Literatura Informativa, duas sobre Arcadismo, uma sobre Shakespeare, uma sobre Montaigne e uma sobre a llíada (cf. FISCHER et ali.. A Literatura no Exame Nacional do Ensino Médio (ENEM), 2012, p. 117-8).

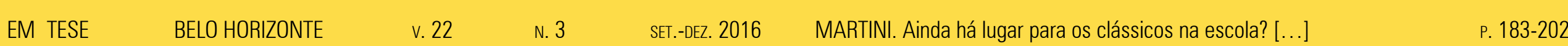


41. FISCHER, O Fim do cânone e nós ensino - Passado e presente do

ensino de literatura no Brasil, 2014.

43. FISCHER et ali. $A$ Literatura no Exame Nacional do Ensino Médio (ENEM), 2012, p. 117. como dissemos no início, não são apenas as práticas letradas do Período Colonial que sofrem dessa preterição "temporal", mas até mesmo os textos da virada do século XIX para o XX, entre os quais os daquele que é considerado nosso "clássico" absoluto, Machado de Assis. E por que isso ocorre?

$\mathrm{Na}$ Matriz de Referência do Exame, encontramos, no que toca especificamente à Literatura, uma ênfase nas relações entre literatura, história e sociedade. Ainda que o documento evite tocar na questão dos Períodos Literários, como também fuja da velha tradição da relação "autor e obra", a reincidência, no texto, de termos como "processo", "processo social”, "continuidade", "ruptura", "formação nacional", "patrimônio literário", denota a preocupação em se relacionar literatura e sociedade, e o papel da primeira na formação da cultura nacional (na esteira do que a LDB de 1971 já trazia), remetendo, no que diz respeito à crítica literária brasileira, à tradição de Antônio Cândido, como aponta Fischer ${ }^{41}$. Como já vimos, esses termos nos remetem também aos PCNEM e aos PCN+. Contudo, se formos relacionar a avaliação das provas do ENEM feita por Fischer [et alii] ${ }^{42}$ aos documentos supracitados, algumas contradições vão aparecer. Em primeiro lugar, vimos como os documentos oficiais para o ensino de literatura incorporaram uma perspectiva histórica ao programa da disciplina, ainda que de forma discreta. Do mesmo modo, a Matriz se vale de termos como "formação" e "patrimônio literário", o qual, por sinal, remete necessariamente ao "cânone”. Olhando-se então para as questões e atentando-se para o fato de que a maioria absoluta delas (81\%) remete o aluno ao panorama literário nacional posterior a 1920, fica-se na dúvida quanto à validade do termo "patrimônio literário" bem como à "formação" que se pretende que o aluno compreenda.

$\mathrm{Na}$ verdade, o ENEM encontra-se muito mais próximo, efetivamente, das disposições apresentadas inicialmente nos PCNEM do que das reformulações posteriores. Nesse sentido, a avaliação encontrada nas Orientações de que as disposições dos PCNEM para o ensino de literatura iriam de encontro às expectativas da sociedade, argumentado que estas não encontrariam respaldo pelo tipo de questões encontradas no ENEM, como mencionamos anteriormente, já não é mais verdade, se é que chegou um dia a ser. Não apenas a centralidade temporal dos textos no século XX e na contemporaneidade buscam um contato com um aluno que, pressupõe-se, não leu e não conhece a "formação" do sistema literário nacional à que se refere à Matriz, mas a valorização de textos "não canônicos" é igualmente um indicativo dessa mesma postura. Ainda segundo Fisher et [alii.], somando-se as questões sobre crônica, canção popular e histórias em quadrinhos, têm-se quase 40\% das questões avaliadas: e isso se pensando apenas nos gêneros tradicionalmente afastados do "cânone" ${ }^{\text {"43 }}$.

Diante disso, é preciso voltar às OCEM e pensar na questão da função da disciplina de Literatura como sendo a de
42. FISCHER et ali.. A Literatura no Exame Nacional do Ensino Médio (ENEM), 2012.

EM TESE $\quad$ BELO HORIZONTE $\quad$ v. $22 \quad$ N. $3 \quad$ SET.-DEz. $2016 \quad$ MARTINI. Ainda há lugar para os clássicos na escola? [...] $\quad$ P. 183-202

\section{Teoria da literatura e Ensino de literatura}


44. COSSON; PAIVA, O PNBE, a literatura $\mathrm{e} o$ endereçamento escolar, 2014, p. 478 promover o letramento literário, de formar o leitor aproximando-o do texto literário e, no caso que nos move, na aproximação dos "clássicos". Para isso, é preciso abordar-se as políticas de incentivo à leitura. Vamos nos concentrar na mais abrangente: o Plano Nacional Biblioteca da Escola (PNBE).

\section{O PNBE}

Conforme explicam Rildo Cosson e Aparecida Paiva, o Plano Nacional Biblioteca da Escola (PNBE) faz parte das políticas públicas de incentivo à leitura, tendo como objetivo a aquisição de obras literárias para compor o acervo das bibliotecas escolares do sistema público de ensino ${ }^{44}$. Apesar de lançado em 1997, um PNBE específico para a literatura no Ensino Médio seria estabelecido apenas em 2009. Com um processo complexo, envolvendo muitos interessados e cifras elevadas, o PNBE, mesmo assim, tem sido conduzido com muita competência e critério. Desde 2006, os editais são praticamente os mesmos. Um quesito, porém, nesses editais chama a atenção e é importante para nossa discussão: a proibição da aquisição de obras em língua portuguesa que estejam em domínio público.

As implicações dessa orientação não passam despercebidas também para Cosson e Paiva. Como analisam os autores, o princípio de tal orientação seria o de não pagar por aquilo que já é gratuito; no caso, há milhares de obras disponíveis gratuitamente no site Domínio Público, por exemplo, incluindo-se entre elas a obra completa de Machado de Assis. No entanto, é preciso que se diga que estar a obra disponível gratuitamente na internet não é o mesmo que estar acessível ao aluno. Este precisa ter um computador, ou tablet, ou algo que o valha para poder ler os arquivos disponibilizados, isso para não mencionar uma conexão com a internet para descarregá-los. Mesmo que se argumente que, na falta disso tudo, o aluno poderia ter acesso a esses livros gratuitos na escola, é preciso ter em mente que, para uma leitura extensiva, como a de um romance machadiano, é inviável que o aluno o faça no laboratório de informática da escola, caso ele exista e funcione, o que se sabe que nem sempre ocorre. Ademais, não se pode pensar na obra apenas como seu conteúdo intelectual; é preciso pensar-se na materialidade do livro, é preciso levar o livro aos alunos, apresentar-lhes o "objeto-livro". Ainda mais quando se trata de obras mais antigas, é aconselhável que o livro seja "amigável” com o leitor, isto é, que apresente paratextos, com contextualizações históricas, glossário etc., que o auxilie a enfrentar uma leitura que geralmente é mais exigente, tanto no que diz respeito à linguagem, quanto às visões de mundo envolvidas. $\mathrm{E}$ tais paratextos não estão disponíveis gratuitamente. Assim, o que ocorre é que tal veto está simplesmente afastando os "clássicos" de língua portuguesa das bibliotecas das escolas e, portanto, das mãos dos jovens leitores.

EM TESE BELO HORIZONTE $\quad$ v. $22 \quad$ N. $3 \quad$ SET.-DEz. 2016 MARTINI. Ainda há lugar para os clássicos na escola? [...] $\quad$ P. 183-202

\section{Teoria da literatura e Ensino de Literatura}


45. COSSON; PAIVA, O PNBE, a mento escolar, 2014, p. 484 .

46. COSSON; PAIVA, O PNBE, a literatura e o endereçamento escolar, 2014, p. 484
No entanto, curiosamente, como também notam Cosson e Paiva, a mesma restrição não se aplica a obras estrangeiras traduzidas para o português. Portanto, ao passo que os "clássicos" compostos em língua portuguesa não podem ser adquiridos pelo programa, os traduzidos de outras línguas podem. Como se não bastasse, o fato de serem obras canonizadas pesa na hora da seleção. Como ilustram os autores, das 180 obras selecionadas em 2013,37\% são de autoria estrangeira e, dessas, $49 \%$ são de domínio público ${ }^{45}$.

Portanto, se o princípio para a não aquisição dessas obras escritas em língua portuguesa, mas em domínio público, é o da economicidade, ele apenas em parte é cumprido no programa, haja vista que, no caso dos clássicos escritos em outras línguas, por exemplo, é possível encontrar muitas traduções também já em domínio público. Pior do que isso, no entanto, é afastar essas obras mais antigas dos alunos, quase que como se não existissem. Curiosamente, tem-se, como resultado inevitável do processo de seleção do PNBE, que literatura contemplada acaba por ser a mesma que também vem sendo contemplada no ENEM: aquela composta depois do Modernismo. Se, por um lado, como apontam Cosson e Paiva, tem-se assim uma literatura "viva" ${ }^{46}$, por estar mais próxima do aluno; por outro, a noção do cultivo de um "patrimônio literário”, como apontam os documentos oficiais, fica completamente comprometida.

\section{QUE LITERATURA SE ESTUDA E/OU SE DEVE}

ESTUDAR NA ESCOLA?

Por um lado, fala-se no fim do cânone; por outro, na necessidade de "abertura" do cânone. De fato, é uma discussão contraditória. Parece haver uma luta entre os que querem derrubar o "cânone" e os que querem preservá-lo; entre inovadores e conservadores. Contudo, para Durão, essa questão, no caso brasileiro, seria irreal: "a ideia de um cânone sufocante, organizado para vangloriar escritores homens, brancos e ocidentais, projeta uma imagem de autoritarismo que é falsa" ${ }^{\text {" }}$. Em primeiro lugar, não haveria uma proibição da circulação e do estudo de textos que estariam "fora do cânone"; em segundo lugar, a pouca relevância dada à literatura no Brasil tornaria a questão ainda mais irreal. Assim, ainda segundo o autor, o cânone teria uma existência fantasmática, no sentido em que existiria como um "inimigo imaginário", que permitiria apenas o surgimento de argumentos de defesa para um debate que, na verdade, não existe. Durão assevera, então, que as "únicas ocasiões nas quais faz algum sentido falar de cânone são nas compras governamentais para as escolas públicas e a lista do vestibular, realizada por professores universitários, nossos colegas" ${ }^{\prime 4}$.

Que há uma predominância de homens brancos na historiografia literária brasileira é inegável; as causas para isso é que são realmente discutíveis, discussão essa que foge,
47. DURÃO, Variações sobre os equivocos do debate do cânone, 2014 , p. 620

48. DURÃO, Variações sobre os equívocos do debate do cânone 2014, p. 619
EM TESE BELO HORIZONTE $\quad$ v. $22 \quad$ N. $3 \quad$ SET.-DEz. 2016 MARTINI. Ainda há lugar para os clássicos na escola? [...] $\quad$ P. 183-202 
49. FISCHER, O Fim do cânone e nós com isso - Passado e presente do ensino de literatura no Brasil, 2014.

50. MELLO, Como se faz um clássico na literatura brasileira?, 2012. porém, do escopo deste texto. Todavia, Durão tem razão em asseverar que, na prática, pelo menos, a questão do "cânone" é uma questão sobre o ensino de literatura, uma questão escolar. No entanto, outro questionamento, que interessa ao nosso tema, impõe-se: defender o estudo dos "clássicos" é a mesma coisa, no Brasil, que defender então o "cânone"?

Acho que aqui, precisamente, é onde devemos fazer algumas considerações. Como bem mostra Fischer ${ }^{49}$, a formação do "cânone brasileiro" está intimamente ligada à universidade e às correntes críticas que nela vigoram. São os professores universitários da área de Literatura os que, via de regra, elaboram as questões da disciplina para os vestibulares e o ENEM e os que participam dos processos de compras de livros para o governo, como o PNBE, para não se falar na elaboração de livros didáticos. Como também demonstrou Mello $^{50}$, é a crítica quem principalmente consagra determinadas obras em detrimento de outras, o que acaba chegando, pelas vias mencionadas, à escola. Surge então uma nova pergunta: o que os críticos estão estudando?

Em pesquisa com a base de dados dos pesquisadores em Letras no Lattes, Eble chegou à conclusão de que estudam justamente o "cânone". Encontrando 1846 citações no Lattes, compreendendo 477 autores diferentes, Eble fez uma lista dos 30 autores mais citados. Só as citações desses autores são responsáveis por quase a metade do total $(49,89 \%)$. Entre os
30 autores mais estudados na academia hoje, apenas seis tiveram sua obra consolidada antes de 1920; dentre essas, nenhuma é anterior ao século XIX ${ }^{51}$. Pelo que é possível entender da pesquisa, só não é "cânone" o que é recente, o que não é necessariamente verdadeiro. Isso à parte, o que se percebe pela pesquisa é a centralidade da crítica no estudo de obras do século XX, posteriores ao Modernismo, como as que acabam aparecendo no ENEM. Interessante, por outro lado, seria saber quantos dentre a miríade dos outros 447 autores citados seriam contemporâneos, pois o artigo não os menciona. Tal comparativo daria uma perspectiva mais significativa aos dados recolhidos pela autora, pois, como se sabe, quanto mais para o passado se vai, mais concentrado fica o rol de autores estudados, ao passo que o contrário ocorre com os autores mais recentes. Assim, se, hipoteticamente, 200 desses autores fossem contemporâneos e responsáveis por $50 \%$ das citações, o resultado da pesquisa seria outro... ${ }^{52}$

De qualquer modo, se a formação de um "cânone" no Brasil está ligada à questão do nacionalismo, como argumentam Reis e Fischer, é preciso se chegar à conclusão necessária de que as obras compostas até o século XVIII não fazem parte do "cânone", a não ser por certa leitura anacrônica - não rara, é bom que se diga, e popularizada pela obra de Afrânio Coutinho ${ }^{53}$ - que encontra, desde a "Carta de Caminha", laivos de nacionalidade. É bem verdade que Vieira e Gregório
51. EBLE, $A$ literatura brasileira a permanência do cânone na academia, 2007.

52. Telles, ao estudar as dissertaçôes e teses desenvolvidas na USP, entre 1937 e 2013, mas na área de Literatura Portuguesa, chegou a uma conclusão similar ao que estamos sugerindo. Enquanto que há oito trabalhos sobre Camões - o "cânone" por excelência das literaturas em língua portuguesa -, há 13 trabalhos sobre música popular, na area de literatura vez há um tran e três sobre música popular, áém de três sobre literatura de cordel. Esses dados levam o autor a questionar a noção de "cânone" e a predominância da influência da universidade sobre sua constituição (cf. TELLES, A literatura como objeto de conhecimento: notas sobre o cânone e a pesquisa acadêmica 2015, p. 42).

53. COUTINHO, Conceito de literatura brasileira, 1960




54. Para uma discussão das possibilidades de incorporar ess literatura na realidade do aluno, MARTIII, Fantasmas no Sótzo: MARTN, Fantasmas no Solao: as

55. Cf. COMPAGNON, O demônio d teoria. Literatura e senso comum 2001, p. 254. de Matos estão nos manuais e livros didáticos, mas o que isso significa de fato? Suas obras são lidas e estudadas? Como se vê, da academia à escola, há um progressivo apagamento da leitura dos "clássicos" em detrimento de autores do século XX, em especial, que, com base em Fischer e Eble, formariam o "cânone" atual, se formos entendê-lo como composto das obras que de fato são estudadas na academia, chegando às provas dos vestibulares e Enem e às compras governamentais. Novas "modas" acadêmicas, como pontua Fischer, trazem novos interesses aos professores de literatura, os quais acabam modificando o "cânone". Nesse sentido, se for realmente possível falar de um "cânone", ele encolheu temporalmente. Antes de Machado e Alencar, o que se tem é uma "pré-história" de nossas letras. Sem interesse crítico, as letras coloniais, "portuguesas", aparecem como uma etapa superada de nossas letras, sem qualquer interesse para o "nosso mundo" 54 ; por isso, então, excluídas das provas e das leituras escolares. Assim, pode-se dizer com certa tranquilidade que os "clássicos", essas obras compostas entre os séculos XVI e XVIII, não fazem mais parte desse "cânone" mencionado acima, caminho que vem sendo seguido a passos largos pelas obras do século XIX e inícios do XX, muitas delas "clássicos" em sentido amplo, obras que continuam a ser pertinentes para nós fora de seu contexto de origem ${ }^{55}$, como as de Machado de Assis, por exemplo. Assim sendo, é preciso perguntar: até que ponto a rejeição ao "cânone" não é, na verdade, pelo menos em parte, um apagamento do antigo em detrimento do novo e sintoma de uma sociedade centrada no presente? E, na esteira dessa pergunta: essa centralidade no novo é pedagogicamente salutar?

Se a questão do "valor" é um limite da teoria, como ensina Antoine Compagnon, isso não tem necessariamente a ver com a seleção de obras para se estudar literatura. No fundo, a discussão do "cânone" é, como, aliás, sempre foi, pedagógica. Serve para pensar o que é que se espera que o aluno saiba de literatura. Se não se pode provar que uma obra é "melhor" que a outra, como os defensores do cânone parecem pretender, pode-se, outrossim, analisar os critérios pelos quais foi avaliada no passado e o é hoje. Por isso, como atestam Compagnon, Avelar, Rechou, dentre outros, não se deve falar em "cânone", mas em "canonização". O que interessa é mostrar justamente o jogo de valores que, por serem culturais, são transitórios. Todas essas ideias já estão, na verdade, nos PCN+ e também nas OCEM, como já se viu. Mas, para fazer isso, não se pode ficar estudando apenas textos de uma mesma época ou optar por iniciar em um momento aleatório, como se nada houvesse existido antes disso.

É claro que há o perigo de se retornar, por isso, às aulas de historiografia literária... No entanto, é exatamente o que vai acontecer se não houver textos para ler. Se o objetivo do ensino de literatura na escola é o de promover o letramento literário, conforme preconizam as OCEM, como forma de



\section{Teoria da literatura e Ensino de Literatura}


56. PINTO, Alguns descompassos no ensino de literatura: documentos práticas oficiais, 2014, p. 460 apresentar um universo que foi historicamente valorizado como meio de distinção social, caso da literatura, fazendo com que todo e qualquer cidadão possa fazer parte dele, afastar o aluno do livro literário é algo nocivo e em absoluta contradição com as políticas de inclusão e de democratização do ensino $^{56}$. E, no tocante ao nosso tema, o fato de o PNBE não permitir a compra de obras escritas em língua portuguesa que estão em domínio público é basicamente uma condenação oficial de tudo que é anterior a meados do século XX ao exílio da leitura, ao "museu literário", onde se aprende que algo existe, mas do qual se mantém um afastamento respeitoso e quase religioso, bem de acordo com a origem do termo "cânone". E é apenas nesse sentido que as obras de que viemos tratando podem se aproximar de um "cânone": pelo afastamento que se tem delas, não pelo seu estudo efetivo.

É daí justamente que a premência de uma conciliação emerge. Georg Otte, pegando emprestado de Walter Benjamin a noção de "imagem dialética", defende a necessidade de um diálogo entre passado e presente. Se o Brasil teve um passado de colonização, ao qual a literatura dos séculos XVI a XVIII encontra-se ligada, sua materialização, em nosso caso, as práticas letradas, não deve ser apagada, como sinal de superação, atitude que, aliás, está na raiz do "cânone" brasileiro de que tratam Fischer e Reis. Deve-se, outrossim, dialogar com esse passado, não como forma de culto, o que caracterizaria um "cânone autoritário", nem como forma de apagamento, o que caracterizaria um cânone "progressista", mas para integrá-lo ao presente, apropriando-se dele, dialeticamente. É essa apropriação que quebra o distanciamento sagrado de um "cânone", o seu caráter de "museu", ou, nos termos de Benjamin, sua "aura"57. Evitar as obras do passado, portanto, denuncia a dificuldade de integrá-las ao presente; e essa dificuldade não reside nas obras, como muito discurso "anticanônico" parece sugerir, esquecendo-se da inexistência de uma imanência denunciada pelo próprio, mas no sujeito em nosso caso, especialmente no professor, seja ele o formador de professores ou o que vai para as escolas ${ }^{58}$.

Assim, como as próprias OCEM trazem, a questão é equilibrar: é preciso ler o antigo, assim como é imprescindível ler o novo. É preciso formar leitores. Para isso é preciso, obviamente, que leiam. Portanto, é necessário que se pense em políticas mais consistentes, teórica e metodologicamente, efetivas e que trabalhem em conjunto, para o ensino de literatura na escola Enfim, é preciso que, em função de dogmatismos, seja o ultraconservador, seja o ultralibertário, não se deixe de pensar pedagogicamente e realisticamente na formação dos leitores.

\section{CONCLUSÃO}

A questão do estudo do cânone literário na escola tem sido posta como uma querela política e defendê-lo, como pactuar com uma postura autoritária e preconceituosa, que exclui a
57. OTTE, $A$ obra de arte e a narrativa: reflexốes em torno do cânone em Walter Benjamin, 1999.

8. Oliveira e Rezende identificam já uma mudança de alguns docentes, que se encaminham para uma busca do que chamam de "contextualização" entre a literatura e o cotidiano de seus alunos. No entanto, o discurso dos professores denuncia como eles mesmos veem a literatura "com distanciamento, como algo Aula de literatura no ensino médio: escombros do texto ou leitura literária, 2015, p. 17).

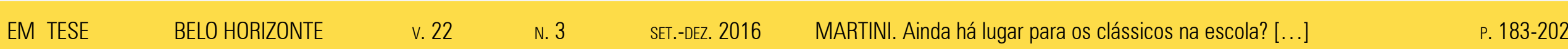


diferença. Como procuramos demonstrar, porém, a questão não é tão simples assim; não só o "cânone" é, por um lado, associado com quase tudo o que é antigo, como, paradoxalmente ao que se espera de um "cânone" legitimado, isto é, dos "clássicos", o que é antigo, por outro lado, é pouquíssimo estudado nas universidades e praticamente não faz mais parte da cultura letrada dos alunos que estão na escola. Nesse sentido, Durão tem razão em afirmar o caráter fantasmático da discussão do "cânone" e ressaltar a relevância eminentemente pedagógica que se lhe deve atribuir. Por isso, defender que se estude, nas universidades e, por extensão, nas escolas, os mecanismos de "canonização" é um passo importante justamente para desmistificar o "cânone", para que se possa integrar as obras do passado ao presente, como defende Otte. As formas como os documentos oficiais lidam com o assunto, contudo, são ambíguas, e o ENEM e o PNBE acabam, de forma intencional ou não, a afastar os "clássicos" ainda mais dos jovens leitores. Por isso, é preciso uma discussão clara e, dentro do possível, isenta, pedagogicamente orientada, sobre que literatura ler na escola, sem se limitar a um conservadorismo que se autolegitima ou à ditadura do novo e do "politicamente correto", não raro calcados, nos dois casos, em anacronismos interpretativos e mistificações ideológicas.

\section{REFERÊNCIAS}

AVELAR, Idelber. Cânone literário e valor estético: notas sobre um debate de nosso tempo. In: Revista brasileira de literatura comparada. Rio de Janeiro: Abralic, 2009. n.15, pp. 113-50.

BRASIL. LEI № 9394, de 20 de dezembro de 1996. Estabelece as Diretrizes e Bases da Educação Nacional (LDB/96). Brasília: MEC, 1996.

Parâmetros Curriculares Nacionais: Ensino Médio. Vol. inguagens, códigos e suas tecnologias. Brasília: MEC/Semtec 1999

PCN+Ensino Médio: Orientações educacionais complementares aos Parâmetros Curriculares Nacionais. Vol. Linguagens, códigos e suas tecnologias. Brasília: MEC/Semtec 2002

Orientações curriculares para o ensino médio:

Linguagens, códigos e suas tecnologias. Ministério da Educação/Secretaria de Educação Básica. Brasília, 2006.

Base Nacional Comum Curricular. 2. ed. rev. Disponível em: http://basenacionalcomum.mec.gov.br/documentos/bncc2 versao.revista.pdf. Acesso em 06 de janeiro de 2017.

BLOOM, Harold. O cânone ocidental. São Paulo: Objetiva, 1995.

COMPAGNON, Antoine. O demônio da teoria. Literatura e senso comum. Belo Horizonte: UFMG, 2001.

COSSON, Rildo: PAIVA, Aparecida. O PNBE, a literatura e o endereçamento escolar In: Remate de Males. Campinas-SP, (34.2): pp. 477-499 , Jul./Dez. 2014
EM TESE

BELO HORIZONTE

v. 22

N. 3

SET.-DEZ. 2016

MARTINI. Ainda há lugar para os clássicos na escola? [...]

P. 183-202

Teoria da literatura e Ensino de literatura 
COUTINHO, Afrânio. Conceito de literatura brasileira. Rio de Janeiro: Ediouro, 1960.

CULLER, Jonathan. Teoria Literária: uma introdução. São Paulo: Beca Produções Culturais, 1999.

DE MARTINI, Marcus. Fantasmas no Sótão: as Letras Coloniais na Escola. In: DE MARTINI, Marcus; OLIVEIRA, Raquel Trentin; FELIPPE, Renata Farias de (Orgs.). Literatura na Escola: teoria, prática e (in)disciplina. Santa Maria: PPGL Editores, 2016.

DURÃO, Fabio Akcelrud. Variações sobre os equívocos do debate do cânone. In: Remate de Males. Campinas-SP, (34.2): pp. 613623, Jul./Dez. 2014

EBLE, Laeticia Jensen. A literatura brasileira e a permanência do cânone na academia. In: Revista Observatório Itaú Cultural - N 17 (ago./dez. 2014). São Paulo: Itaú Cultural, 2007, p. 142-153.

FREDERICO, Enid Yatsuda: OSAKABE, Haquira. PCNEM literatura. Análise crítica. In: BRASIL. Ministério da Educação (MEC). Secretaria de Educação Básica (SEB). Departamento de Políticas de Ensino Médio. Orientações curriculares do ensino médio. Brasília: MEC, SEB, 2004

FISCHER, Luís Augusto; LUFT, Gabriela; FRIZON, Marcelo; LEITE, Guto; LUCENA, Karina; VIANNA, Carla; WELLER, Daniel. A Literatura no Exame Nacional do Ensino Médio (ENEM). In: Nonada: Letras em Revista. Porto Alegre, ano 15, n. 18, p. 111-126, 2012.

O Fim do cânone e nós com isso - Passado e presente do ensino de literatura no Brasil. in: Remate de Males. Campinas-SP, (34.2): pp. 573-611, Jul./Dez. 2014
GINZBURG, Jaime. Cânone e valor estético numa teoria autoritária da literatura. In: Revista de Letras. 44(1): pg. 97-111. São Paulo, 2004.

O Valor Estético: Entre Universalidade e Exclusão. In: Alea Volume 10, Número 1, Janeiro-Junho 2008, p. 98-107.

HANSEN, João Adolfo. Barroco, Neobarroco e outras ruínas. In: Floema especial - ano II. Universidade Estadual do Sudoeste da Bahia, n. 2 A, p. $15-84$, Outubro, 2006.

MELLO, Marisa Schincariol de. Como se faz um clássico na literatura brasileira? Análise da consagração literária de Érico Veríssimo, Graciliano Ramos, Jorge Amado e Rachel de Queiroz (1930-2012). 2012. Tese (Doutorado em História) - Instituto de Ciências Humanas e Filosofia da Universidade Federal Fluminense, Niterói, 2012.

OLIVEIRA, Gabriela Rodella de; REZENDE, Neide Luzia de. Aula de literatura no ensino médio: escombros do texto ou leitura literária? In: Todas as Letras, São Paulo, v. 17, n. 3, p. 13-24, ago./ dez. 2015.

OSAKABE, Haquira; FREDERICO, Enid Yatsuda. Literatura.

Orientações curriculares do ensino médio. Brasília: $\mathrm{MEC} / \mathrm{SEB} /$ DPPEM, 2004.

OTTE, Georg. A obra de arte e a narrativa: reflexões em orno do cânone em Walter Benjamin. In: OLIVEIRA, Silvana Pessoa; OTTE, Georg. Mosaico crítico: ensaios sobre literatura contemporânea. Belo Horizonte: Autêntica; NELAM-FALE/UFMG, 1999. 
PAULINO, Graça. Formação de leitores: a questão dos cânones literários. In: Revista Portuguesa de Educação, vol. 17, núm. 1 2004, pp. 47-62, Universidade do Minho, Braga, Portugal.

PINTO, Mayra. Alguns descompassos no ensino de literatura:

documentos e práticas oficiais. In: Remate de Males. CampinasSP, (34.2): pp. 459-476, Jul./Dez. 2014.

RAZZINI, Márcia de Paula Gregorio. O espelho da nação: a

Antologia Nacional e o ensino de português e de literatura (1838-

1971). Tese (doutorado), Universidade Estadual de Campinas,

Instituto de Estudos da Linguagem. Campinas, SP, 2000.

RECHOU, Blanca-Ana Roig. Educação literária e cânone literário escolar. In: Letras de Hoje, Porto Alegre, v. 45, n. 3, p. 75-79, jul./ set. 2010.

REIS, Roberto. Cânon. In: JOBIM, João Luís (Org.). Palavras da crítica. Rio de Janeiro: Imago, 1992.

SEGABINAZI, Daniela Maria. Orientações e diretrizes para o

ensino e a formação do professor de literatura. In: Diadorim, Rio de Janeiro, Revista 18 volume 1, p. 58-76, Jan-Jun 2016.

TELLES, Luís Fernando Prado. A literatura como objeto de

conhecimento: notas sobre o cânone e a pesquisa acadêmica.

In: Revista FronteiraZ - no 14 - Julho de 2015, pp. 30-50. 